\title{
Ozone Production in Cylindrical Co-axial Double Dielectric Barrier Discharge Ozone Generator
}

\section{Gobinda Prasad PANTA ${ }^{1, *}$, Hom Bahadur BANIYA ${ }^{1,2}$, Santosh DHUNGANA ${ }^{1}$, Deepak Prasad SUBEDI ${ }^{1}$ and Antonis PAPADAKI ${ }^{3}$}

\author{
${ }^{I}$ Department of Physics, School of Science, Kathmandu University, Dhulikhel, Kavre, Nepal \\ ${ }^{2}$ Department of Physics, Tri-Chandra Multiple Campus, Tribhuvan University, Nepal \\ ${ }^{3}$ Department of Electrical Engineering, Computer Engineering and Informatics, School of Engineering, \\ Frederick University, Nicosia, Cyprus
}

("Corresponding author's e-mails: gobindapanta@yahoo.com, gppanta@ku.edu.np)

Received: 14 April 2020, Revised: 19 May 2021, Accepted: 25 May 2021

\begin{abstract}
This study developed an ozone generator of a double co-axial cylindrical dielectric barrier discharge system with air, argon, and oxygen as the working gases. The discharge was produced by using a high voltage power supply of $0-18 \mathrm{kV}$ and a line frequency of $50 \mathrm{~Hz}$. The flow rate of air, argon, and oxygen was varied from 1 to $6 \mathrm{~L} / \mathrm{min}$. A comparison of $\mathrm{O}_{3}$ generation in air, argon, and oxygen using brass as a central electrode was conducted and it was found that $\mathrm{O}_{3}$ concentration was higher in the case of oxygen than in the air and in argon gases environment for given fixed discharge time, applied voltage, and diameter of the brass electrode. This study revealed that the concentration of ozone increased along with the increase in the applied voltage for constant discharge time and gas flow rate. The $\mathrm{O}_{3}$ concentration also increased with the increase in the discharge time at fixed applied voltage and gas flow rate; however, the concentration decreased with the increase in the gas flow rate at fixed discharge time, applied voltage, and diameter of the electrode. A small reactor with a large inner electrode generated a high concentration of $\mathrm{O}_{3}$. Yet, a reactor with a small diameter, there seemed to have an optimum inner electrode diameter. The glass tube reactor of the internal diameter of $18 \mathrm{~mm}$ and the brass electrode of diameter $8 \mathrm{~mm}$ were utilized in this study. The ozone concentration was higher for oxygen as feed gas than both in the air and in argon and the $\mathrm{O}_{3}$ concentration was also higher in the air than in argon at fixed discharge time, applied voltage, and diameter of ozone generator.
\end{abstract}

Keywords: Applied voltage, Brass electrode, Double dielectric barrier discharge, Ozone, Ozone analyzer

\section{Introduction}

Dielectric Barrier Discharge (DBD) non-thermal or cold plasma reactor enables the production of plasma active species at atmospheric pressure without expensive vacuum systems. The emission of UV light and the generation of radicals and charged particles contribute to the destruction of microorganisms in cold plasmas [1,2]. DBD technique is used for the generation of ozone and is most commonly produced in the filamentary mode when operated at atmospheric pressure [3]. DBD technique finds its extensive applications in waste gas treatment, surface activation and treatment, carbon dioxide laser, excimer lamps, and plasma screens [2-4]. A low line frequency $(50 \mathrm{~Hz}) \mathrm{AC}$ source consisting of a conventional step-up transformer and a variac may be the best choice for the formation of ambient air DBDs [5]. 
http://wjst.wu.ac.th

DBD generator, in which a small gap is formed for gas flow by inserting at least 1 dielectric layer on the surface of one of the electrodes, has always been considered as the reliable way to generate ozone by researchers and due to its strong oxidizing property and environmentally friendly nature.

Ozone sees an increasing demand for considerable industrial applications including in food chemistry, medicine, water treatment, plasma-assisted combustion an flue gas treatment and successfully used in the wide industrial application including bacteria, algae, spores killing and vanishing volatile organic compounds, odor treatment, enhancing fertilization purification of ambient air and potable water, disinfecting food products to increase shelf life; fumigation of operation theaters in hospitals, sterilization of operational tools and personnel $[6,7]$.

When air is passed through the $\mathrm{DBD}$, the interaction of high-energy electrons with the oxygen molecules within the inter-electrode space may give rise to the dissociation of oxygen molecules [8]. Ozone is formed from oxygen atoms with $\mathrm{O}_{3}$ chemical symbol. Ozone is a relatively unstable molecule compared to oxygen, which is very relatively stable. Ozone naturally can be formed by UV radiation, through the method of sunlight, which can reduce oxygen gas in the air. $\mathrm{O}_{3}$ is smell or odor irritating, colorless, capable of oxidizing organic compounds [9]. Ozone is a powerful oxidizing agent of the oxidation potential of $2.07 \mathrm{~V}$. It has relatively higher disinfection potential than chlorine and other disinfectants [10]. Ozone finds its application mainly in water treatment and air purification [11,12].

The oxygen molecule breaks down into 2 radicals oxygen then reacts with oxygen to form ozone [13]. Ozone is far more efficient in killing bacteria, viruses, spores, and cysts [14,15]. This study aims to design of ozone generator by double dielectric barrier discharge of glass tube to generate ozone in air, argon, and oxygen gases environment at atmospheric pressure.

\section{Materials and methods}

\section{Ozone production mechanism in double DBD reactor} [16-24].

The role of electrons generated in electrical discharge is to excite and dissociate oxygen molecules

$\mathrm{e}+\mathrm{O}_{2} \rightarrow \mathrm{O}+\mathrm{O}+\mathrm{e}$

$\mathrm{O}+\mathrm{O}_{2} \rightarrow \mathrm{O}_{3}$

where e is the charge of the electron, $\mathrm{O}$ is atomic oxygen, $\mathrm{O}_{2}$ is the oxygen molecule and $\mathrm{O}_{3}$ is the ozone molecule.

$\mathrm{O}+\mathrm{O}_{2}+\mathrm{O}_{2} \rightarrow \mathrm{O}_{3}+\mathrm{O}_{2}$

$\mathrm{O}+\mathrm{O}_{2} \rightarrow 2 \mathrm{O}_{2}$

$2 \mathrm{O}_{2} \rightarrow 3 \mathrm{O}_{2}$

$3 \mathrm{O}_{2} \rightarrow 2 \mathrm{O}_{3}$

The ozone formation reaction is given by [18-26]:

$\mathrm{M}+\mathrm{O}+\mathrm{O}_{2} \rightarrow \mathrm{O}_{3}+\mathrm{M}$
$\mathrm{O}+\mathrm{O}+\mathrm{M} \rightarrow \mathrm{M}+\mathrm{O}_{2}$

In air discharge, $\mathrm{M}$ represents molecular $\mathrm{N}_{2}$ or $\mathrm{O}_{2}$. The ozone yield of a process depends on both concentration and input electric energy density with efficiency $\eta$ in $\mathrm{g} / \mathrm{kWh}$ which can be estimated by the following equation [24]. 
http://wjst.wu.ac.th

$\eta=\mathrm{C}\left(\mathrm{O}_{3}\right) \mathrm{F}_{\mathrm{r}} / \mathrm{P}$

where $\mathrm{C}\left(\mathrm{O}_{3}\right)$ is the ozone concentration in ppmv, $\mathrm{F}_{\mathrm{r}}$ is the gas flow rate $(\mathrm{L} / \mathrm{min})$ and $\mathrm{P}$ is the discharge power $(\mathrm{kW})$.

\section{Experimental set-up and procedures description}

The production of $\mathrm{O}_{3}$ by cylindrical DBD was designed to find the optimum condition for higher $\mathrm{O}_{3}$ concentration in cylindrical glass tube reactor in the air, in argon, and in oxygen at atmospheric pressure. The schematic diagram of the experimental set-up for the production of $\mathrm{O}_{3}$ and its measurement is shown in Figure 1. A high voltage AC source having a voltage of $0-18 \mathrm{kV}$ and frequency of $50 \mathrm{~Hz}$ was applied to co-axial cylindrical geometry of glass tube reactor of internal diameter $18 \mathrm{~mm}$ and thickness $1 \mathrm{~mm}$. The discharge was generated via line frequency of $50 \mathrm{~Hz}$ high voltage (maximum peak to the peak value of $50 \mathrm{kV}$ ) power supply which was simply a step-up transformer with an HT/LT ratio of 78.26. The central electrode was connected to the high voltage power supply through a ballast resistor of resistance $15 \mathrm{M} \Omega$ in series to limit the current and to avoid overheating of the DBD reactor was the total effective impedance of the DBD reactor. The outer electrode was grounded through a shunt resistor of resistance $10 \mathrm{k} \Omega$ across which the discharge current and voltage were measured. The central electrode was made up of a brass rod of diameter $8 \mathrm{~mm}$, fixed inside the glass tube. The brass electrode was used for its resistance to oxidation and corrosion when exposed to ozone. The dielectric layers were glass tubes. Although the quartz window is better in spectral transmittance than glass, glass has been conveniently obtained, as they are economically available. Two ports on the top and bottom cover of the reactor were used as the gas inlet and outlet. Aluminum foil wrapped outside the glass tube acted as an outer electrode. Air, argon, and oxygen were used as the working gases. The $\mathrm{O}_{3}$ concentration was measured by using ozone analyzer BMT 964 after the discharge was formed. The air passed inside the tube through the gap between the 2 glasses and it was supplied by air blower and argon and oxygen were supplied through gas cylinders. The ozone analyzer can measure ozone concentration from 0 to 5000 ppmv after warm-up pressure and time.

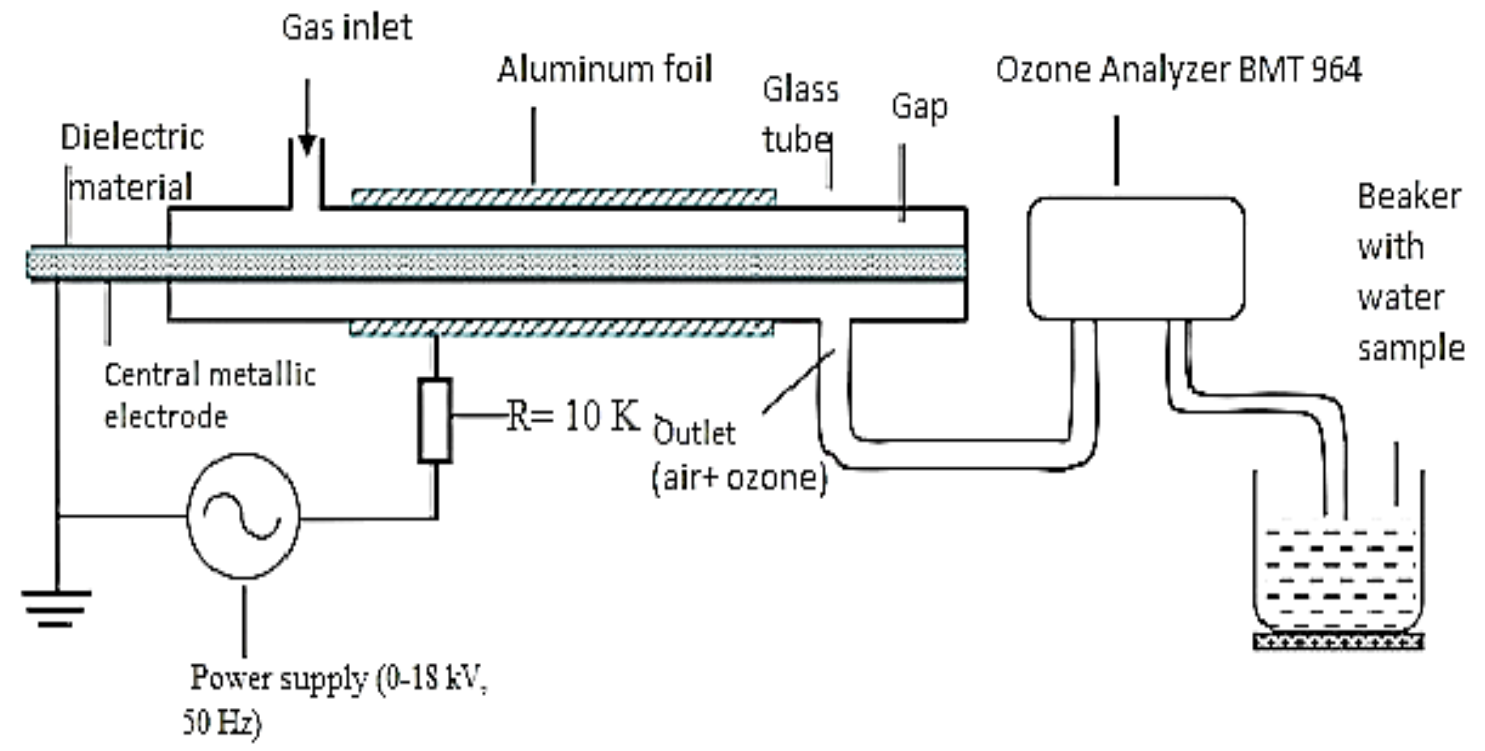

Figure 1 Schematic diagram of ozonizer for production of ozone. 


\section{Results and discussion}

Figure 2 shows the plot of $\mathrm{O}_{3}$ concentration with applied voltage at fixed discharge time 1 min for a fixed flow rate of air and argon 2 and $1 \mathrm{~L} / \mathrm{min}$, respectively for the brass central electrode of diameters 8 $\mathrm{mm}$ using a double dielectric glass having thickness $1 \mathrm{~mm}$ and reactor of internal diameter $18 \mathrm{~mm}$. Figure 3 shows the plot of $\mathrm{O}_{3}$ concentration with discharge time at fixed applied voltage of $17.28 \mathrm{kV}$ for a constant flow rate of air 2 and argon $1 \mathrm{~L} / \mathrm{min}$, respectively for brass central electrode of diameters 8 $\mathrm{mm}$. Figure 4 shows the plot of $\mathrm{O}_{3}$ concentration with air, argon, and oxygen flow rate at applied voltage $17.28 \mathrm{kV}$ for constant discharge time of $1 \mathrm{~min}$ for the brass central electrode of diameters $8 \mathrm{~mm}$. Figure 5 shows the plot of $\mathrm{O}_{3}$ concentration versus gas flow rate for the brass electrode of diameter $8 \mathrm{~mm}$ and reactor of internal diameter $18 \mathrm{~mm}$ at fixed applied voltage of $17.28 \mathrm{kV}$ and discharge time $1 \mathrm{~min}$. From Figures 2(a) - 2(b), it was found that ozone concentration increases with increasing applied voltage at fixed discharge time and fixed gas flow rate for both air and argon environments. This is because of the increase in applied voltage, the electrical energy density also increases i.e. more energy transferred to electrons which means increasing the possibility of collision of the air and oxygen in the reactor chamber. A voltage increase can produce a higher electric field between 2 electrodes. A high enough electric field can accelerate electrons, molecules, or ions causing non-elastic collisions and the number of molecules ionized, radicalized, excited. Consequently, under this condition, the ionization, excitation, dissociation process can be continued. The molecules of oxygen are excited as well as radicalized, thus the chemical reactions should be increased, and ozone is produced. However, supplied energy may not always be sufficient for recombination of ions, radicals, etc. This is because of the residence time of the gas in the ozone chamber. Ozone concentration was high in the case of air as feed gas than argon due to inert gas nature of argon which need more applied voltage for a long discharge time to generate ozone and argon reduces the dissociation of oxygen molecules to form nascent oxygen to combine with an oxygen molecule to produce ozone. From Figure 3(a) - 3(b), it was found that ozone concentration increases with increasing discharge time and found more in the air than in argon. Ozone concentrations increase with increasing discharge time. This is due to the increase of ozone concentration with increasing non-elastic collisions with oxygen molecules. This is due to the reason that ozone concentration increases with an increasing amount of non-elastic collisions with oxygen molecules. It is caused by reduced gas residence time with the increase of flow rate. Reaction to the formation of ozone in the discharge forms $\mathrm{O}_{2}$ dissociation due to collision with electrons where at a constant flow rate, based on the number of the 3 body reaction rates, it is much slower compared to the dissociation of electron collision impact. The residence time of gas on the reactor chamber is inversely related to the airflow rate. Increasing residence time providing time for a reactor to occur and a correspondingly more ozone concentration to be formed. This is because of the residence time of the gas in the ozone chamber. From Figures 4(a) - 4(c) and 5, the ozone concentration decreases with increasing gas flow rate. The reason is the composition of air which is more complex and consists of different species such as $\mathrm{Ar}, \mathrm{N}_{2}, \mathrm{O}_{2}, \mathrm{He}, \mathrm{H}_{2}$, etc. The ozone production is gradually suppressed when the flow rate increases because atom $\mathrm{O}$ generated runs out more quickly following the flow rate of the gas that comes out more quickly, without causing any ozone production so the concentration decreases with the increase of flow rate. The low concentration of ozone with feed gas air has a low number of oxygen molecules per unit volume of air. When the applied voltage increases the ozone begins to be formed and its concentration increases rapidly with applied voltage for all values of the flow rate. The gas flow rate itself also affects the ozone generation efficiency because of the increasing cooling rate with air-cooled ozone reactor. The ozone concentration is found to be more in oxygen than in both air and argon. This is because oxygen easily combines with atomic oxygen to generate ozone in the generator than air which is more complex and argon is an inert gas which produce low ozone concentration than air. The effects of gap spacing on the electric field and power density in the discharge, larger discharge gap leads to the formation of a significantly different kind of discharge. 


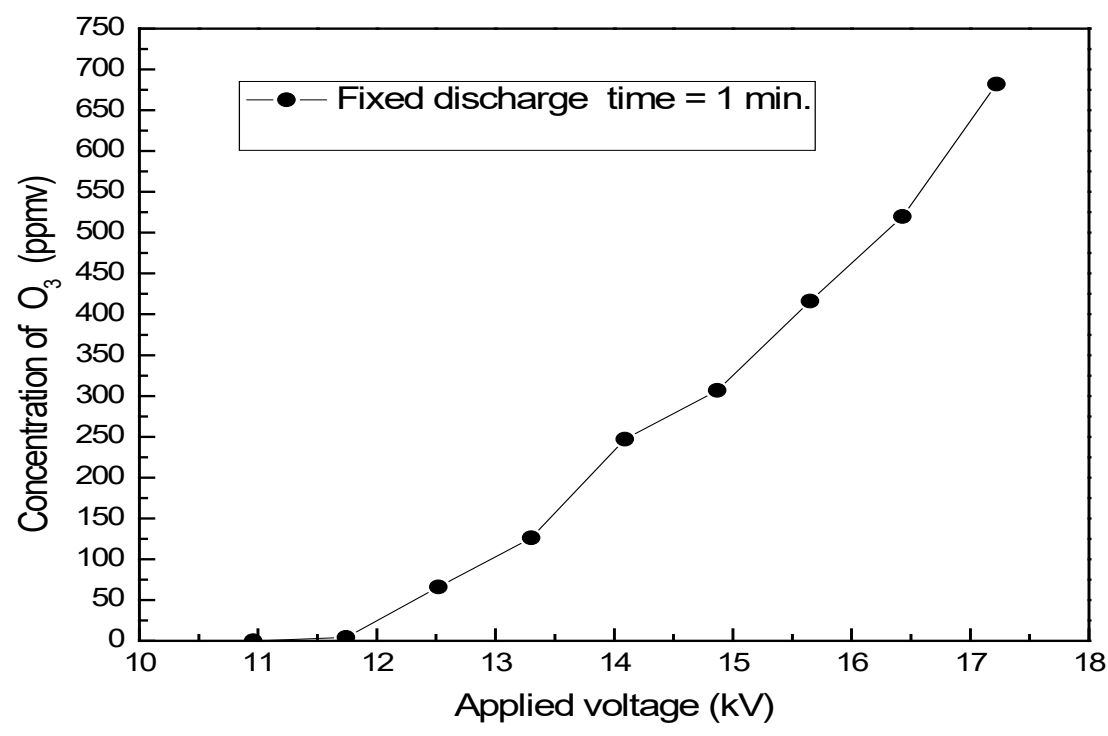

(a)

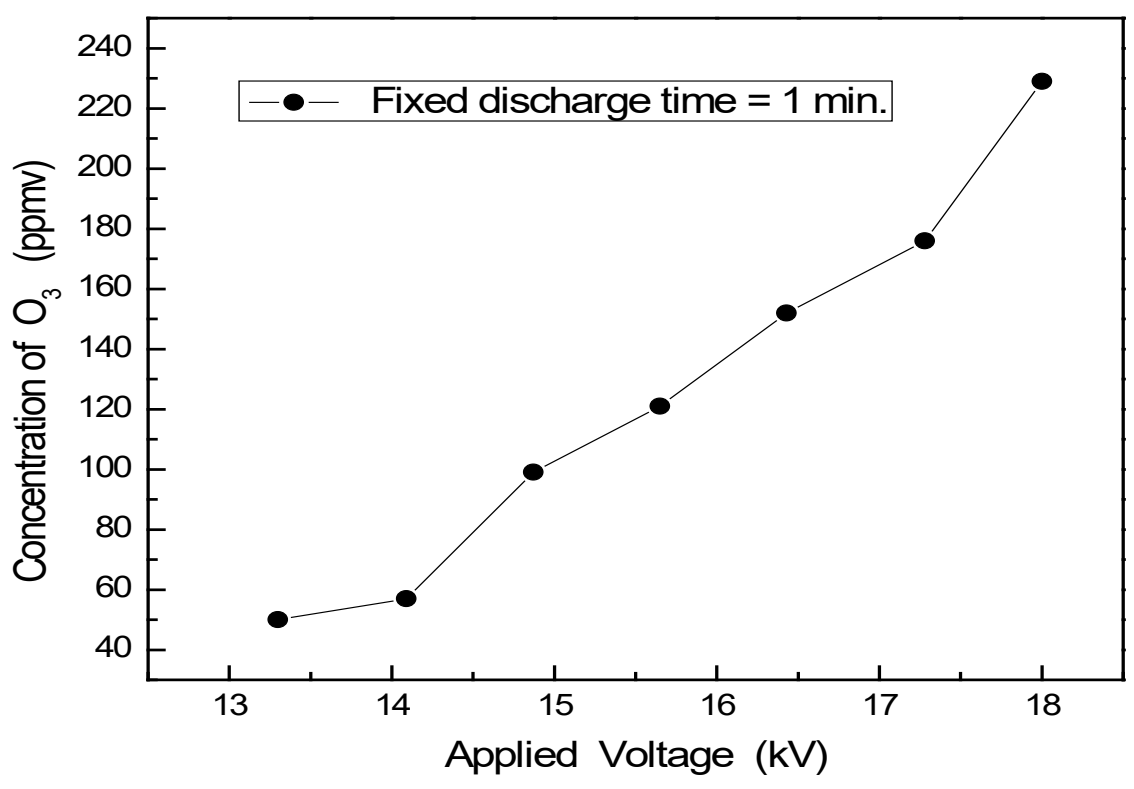

(b)

Figure 2 Plot of $\mathrm{O}_{3}$ concentration versus applied voltage for the brass electrode of diameter $8 \mathrm{~mm}$ and reactor of internal diameter $18 \mathrm{~mm}$ in (a) Air (b) Air + Ar (fixed airflow rate $2 \mathrm{~L} / \mathrm{min}$ and Ar flow rate 1 $\mathrm{L} / \mathrm{min})$. 


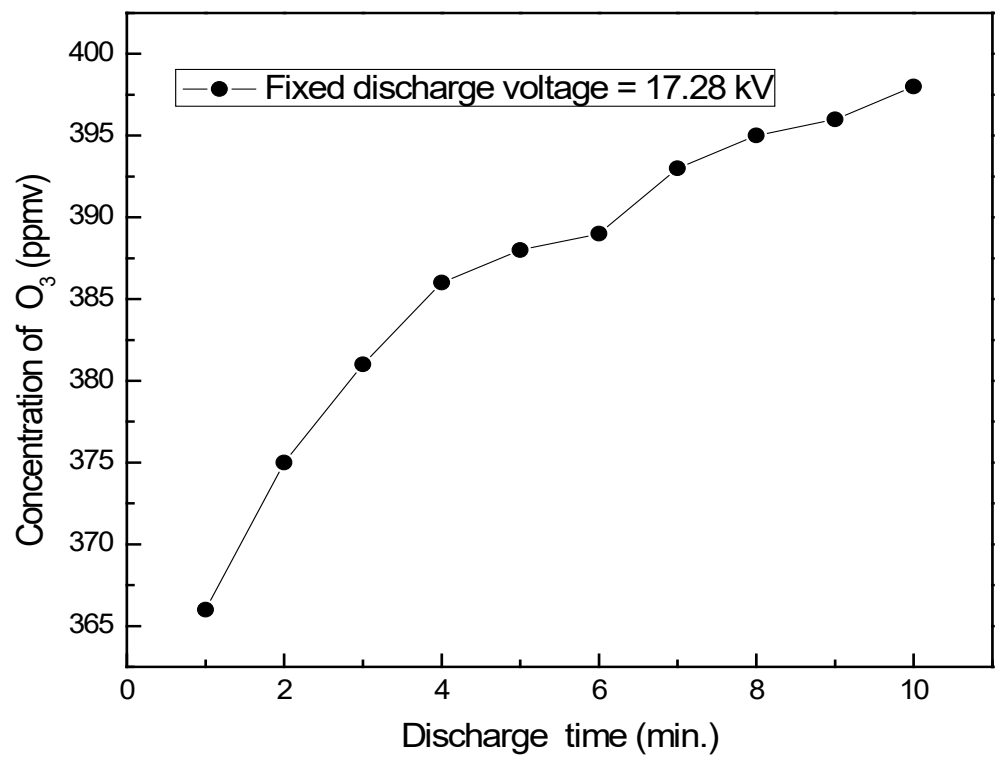

(a)

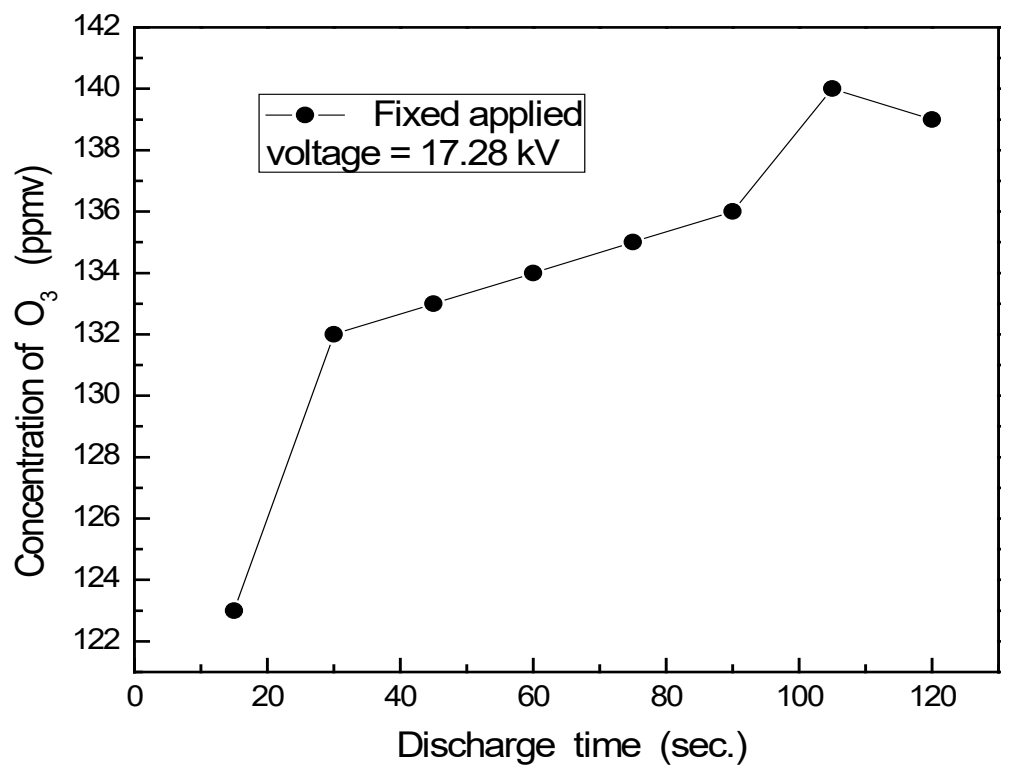

(b)

Figure 3 Plot of $\mathrm{O}_{3}$ concentration versus discharge time for the brass electrode of diameter $8 \mathrm{~mm}$ and reactor of internal diameter $18 \mathrm{~mm}$ in (a) Air (b) Air $+\operatorname{Ar}$ (fixed airflow rate $2 \mathrm{~L} / \mathrm{min}$ and Ar flow rate 1 $\mathrm{L} / \mathrm{min})$. 


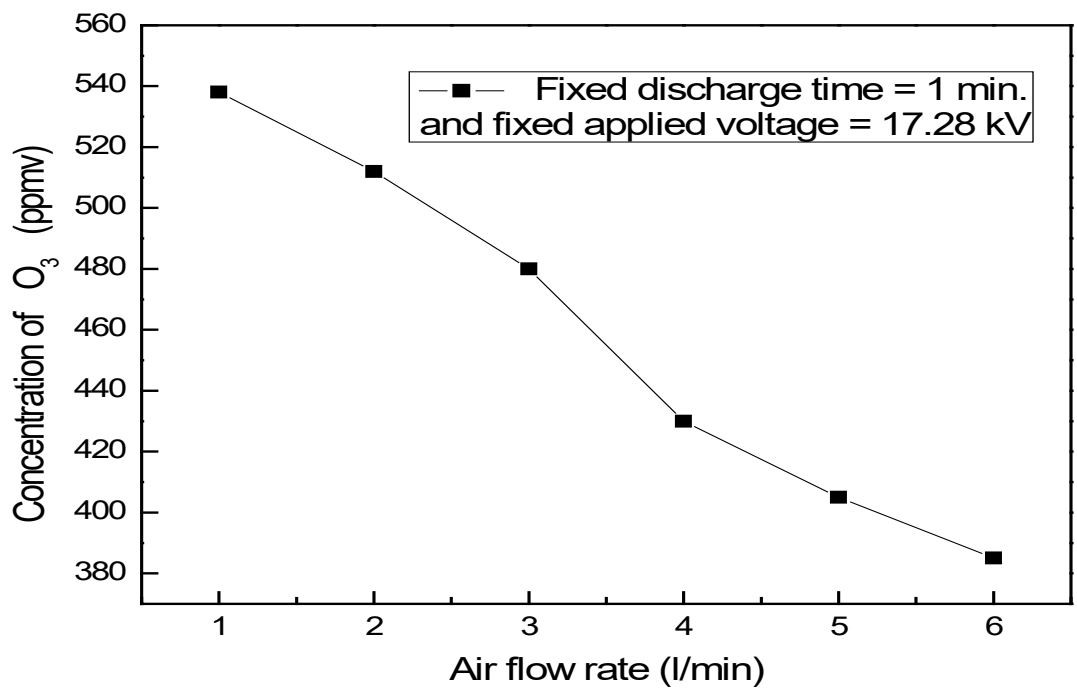

(a)

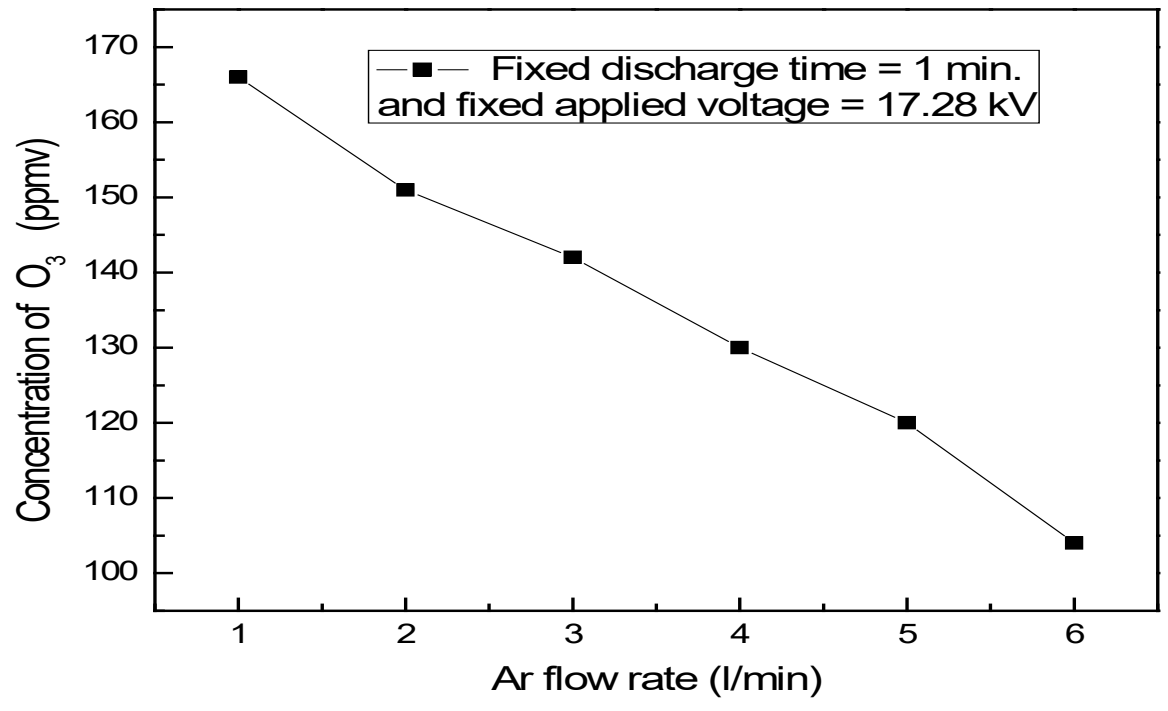

(b) 


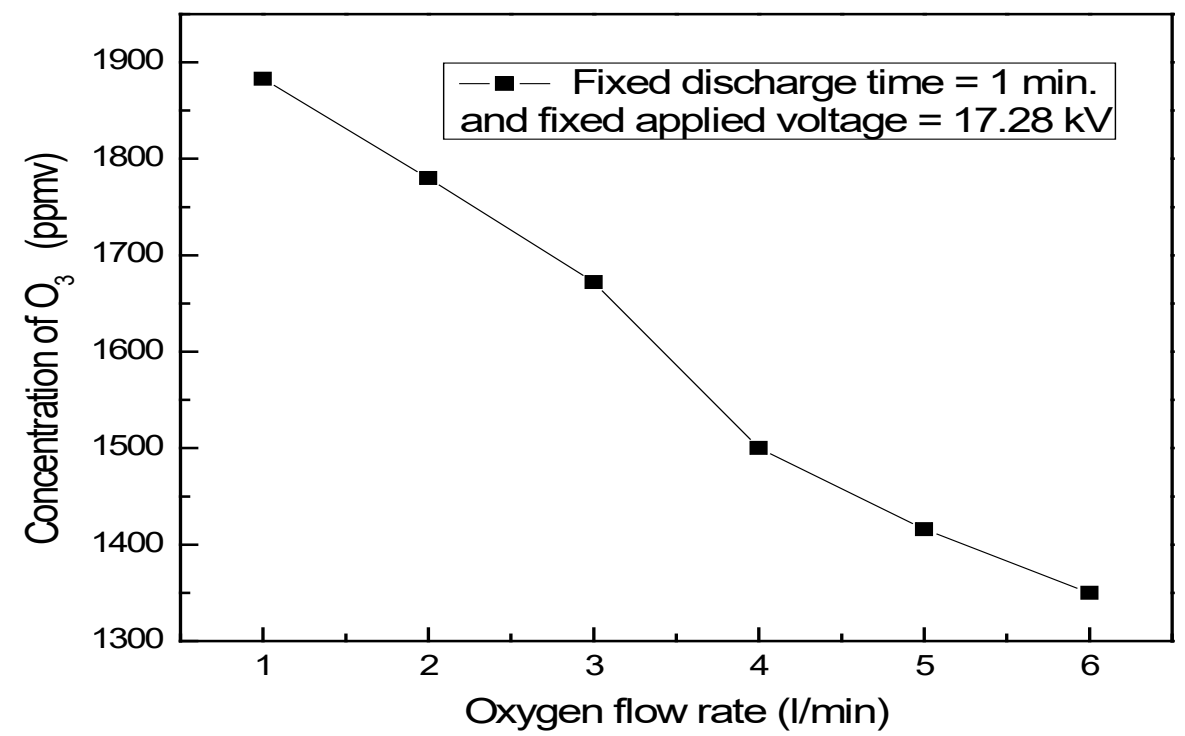

(c)

Figure 4 Plot of $\mathrm{O}_{3}$ concentration versus flow rate for the brass electrode of diameter $8 \mathrm{~mm}$ and reactor of internal diameter $18 \mathrm{~mm}$ at a fixed applied voltage of $17.28 \mathrm{kV}$ and discharge time $1 \mathrm{~min}$ in (a) Air (b) $\mathrm{Air}+\mathrm{Ar}(\mathrm{c}) \mathrm{Air}+\mathrm{O}_{2}$.

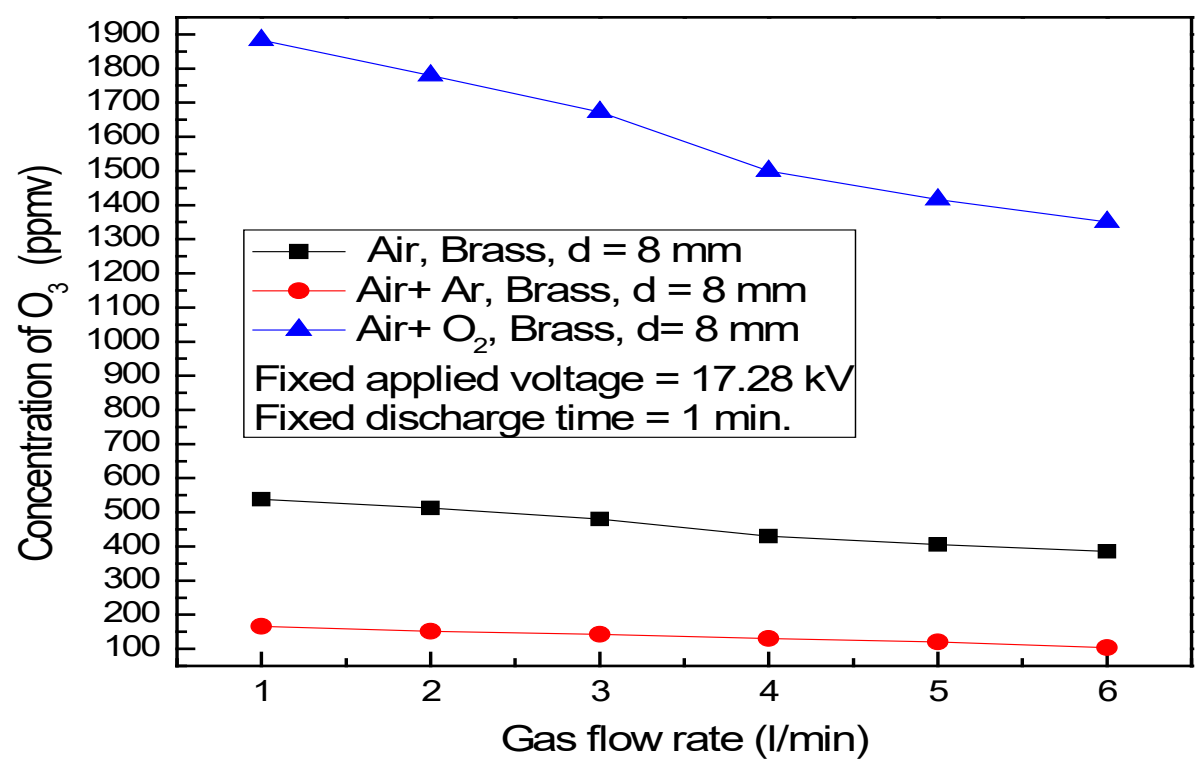

Figure 5 Plot of $\mathrm{O}_{3}$ concentration versus gas flow rate for the brass electrode of diameter $8 \mathrm{~mm}$ and reactor of internal diameter $18 \mathrm{~mm}$ at a fixed applied voltage of $17.28 \mathrm{kV}$ and discharge time $1 \mathrm{~min}$. 
http://wjst.wu.ac.th

\section{Conclusions}

In this work, we have found that ozone concentration increases with increasing applied voltage at fixed discharge time and gas flow rate. This concentration also increases with increasing discharge time at fixed applied voltage and gas flow rate. But this concentration decreases with increasing the gas flow rate. For an efficient and cost-effective ozone yield, smaller reactor and larger inner electrode will achieve better energy efficiency at the same specific energy density in that the mean electron energy is higher so that most of the energy can be used to produce atomic oxygen, the precursor for ozone formation. But for reactors with small diameters, there exists an optimum inner electrode diameter. We have developed an ozone generator and used brass as a central electrode and air, argon, and oxygen as the feed gases to produce ozone. The ozone concentration was higher when using oxygen as feed gas than air and argon for fixed discharge time, applied voltage, and reactor diameter. The gap space is optimized in the ozone generator to increase $\mathrm{O}_{3}$ concentration, yield, and efficiency.

\section{Acknowledgements}

The corresponding author would like to acknowledge the Erasmus Mundus INTACT Project Program which has been funded with support from the European Commission of European Union for $\mathrm{Ph} . \mathrm{D}$. study and research during 6 months at the Department of Electrical Engineering, Computer Engineering and Informatics, School of Engineering, Frederick University, Nicosia, Cyprus. The corresponding author is grateful to Prof. Dr. Christos Themistos, Dean, School of Engineering, Frederick University, Nicosia, Cyprus for his help, suggestion, and support to conduct this research work. The corresponding author also would like to acknowledge all staff members of the Office of the Directorate of Research, Development, and Innovation (RDI), KU for providing research grants to conduct project work. The authors would like to acknowledge Plasma Physics Laboratory, Department of Physics, School of Science, Kathmandu University, Dhulikhel, Kavre, Nepal for getting the opportunity to do this research work.

\section{References}

[1] DP Subedi, RB Tyata, R Shrestha and CS Wong. An experimental study of atmospheric pressure dielectric barrier discharge in argon. AIP Conf. Proc. 2014; 103, 103-8.

[2] Y Bellebna and A Tilmatine. Application of dielectric surface barrier discharge for air disinfection. Acta Electrotechnica et Informatica 2013; 13, 22-6.

[3] Y Qin, S Qian, C Wang and W Xia. Effects of nitrogen on ozone synthesis in packed-bed dielectric barrier discharge. Plasma Sci. Tech. 2018; 20, 1-6.

[4] S Boonduang and P Limsuwan. Effect of generating heat on ozone generation in dielectric cylindercylinder DBD ozone generator. Energ. Power Eng. 2013; 5, 523-7.

[5] HH Al-Jobouri and HO Ismaeel. Design an ozone generator by using dielectric barrier discharge. $J$. Al-Nahrain Univ. Sci. 2014; 17, 89-94.

[6] D Yuan, Z Wang, Y He, S Xie, F Lin, Y Zhu and K Cen. Ozone production with dielectric barrier discharge from air: The influence of pulse polarity. Ozone Sci. Eng. 2018; 40, 494-502.

[7] R Shrestha, UM Joshi and DP Subedi. Experimental study of ozone generation by atmospheric pressure dielectric barrier discharge. Int. J. Recent Res. Rev. 2015; VIII, 24-9.

[8] DP Subedi, RB Tyata, A Khadgi and CS Wong. Physicochemical and microbiological analysis of drinking water treated by using ozone. Sains Malaysiana 2012; 41, 739-45.

[9] PF Hsieh and TY Wen. Evaluation of ozone removal by spent coffee grounds. Sci. Rep. 2020; 10, 124.

[10] Y Bellebna, R Ouiddir, S Nemmic and A Tilmatine. Application of dielectric surface barrier discharge for food storage. Leonardo J. Sci. 2015; 26, 17-28.

[11] M Nur, A Supriati, DH Setyaningrum, Gunawan, M Munir and S Sumariyah. Ozone generator by using dielectric barrier discharge plasma technology with spiral-cylinder configuration: Comparison between oxygen and air as sources. Berkala Fisika 2009; 12, 69-76. 
http://wjst.wu.ac.th

[12] W Tay, S Yap and C Wong. Electrical characteristics and modeling of a filamentary dielectric barrier discharge in atmospheric air. Sains Malaysiana 2014; 43, 583-94.

[13] M Masfufah, A Rahardian, S Maftuhah, E Yulianto, S Sumariyah and M Nur. Analysis of ozone production for medical with double dielectric barrier discharge (DDBD) plasma technology against spiral: Mesh electrode combination. AIP Conf. Proc. 2020; 2197, 040004.

[14] R Bhatta, R Kayastha, DP Subedi and R Joshi. Treatment of wastewater by ozone produced in dielectric barrier discharge. J. Chem. 2015; 2015, 648162.

[15] DP Subedi, RB Tyata, A Khadgi and CS Wong. Treatment of water by dielectric barrier discharge. J. Sci. Tech. Tropics 2009; 5, 117-23.

[16] A Rahardian, M Masfufas, S Maftuhah, E Yulianta, S Sumariyah and M Nur. Effective medical ozone production using mesh electrodes in double dielectric barrier type plasma generators. AIP Conf. Proc. 2020; 2197, 040002.

[17] K Shimizu, S Muramatsu, T Sonoda and M Blajan. Water treatment by low voltage discharge in water. Int. J. Plasma Environ. Sci. Tech. 2010; 4, 58-64.

[18] Z Wang, S Jiang and K Liu. Treatment of wastewater with high conductivity by pulsed discharge plasma. Plasma Sci. Tech. 2014; 16, 688-94.

[19] DV Nguyen, PQ Ho, TV Pham, TV Nguyen and L Kim. Treatment of surface water using cold plasma for domestic water supply. Environ. Eng. Res. 2019; 24, 412-7.

[20] E Yulianto, M Restiwijaya, E Sasmita, F Arianto, AW Kinandana and M Nur. Power analysis of ozone generator for high capacity production. J. Phys. Conf. 2019; 1170, 012013.

[21] AW Kinandana, E Yulianto, AD Prakoso, A Faruq, AM Hendra, E Sasmita, M Restiwijaya, SH Pratiwi, F Arianto and M Nur. The comparison of ozone production with dielectric barrier discharge plasma reactors series and parallel at atmospheric pressure. J. Phys. Conf. 2019; 1217, 012010.

[22] M Benyamina, K Khadidja, F Ghaleb and A Belasri. Influence of the gas temperature in ozone production of mixture $\mathrm{N}_{2}-\mathrm{O}_{2}$. J. Chem. Chem. Eng. 2012; 6, 391-5.

[23] NN Morgan. Atmospheric pressure dielectric barrier discharge chemical and biological Applications. Int. J. Phys. Sci. 2009; 4, 885-92.

[24] Z Buntat, IR Smith and NAM Razali. Ozone generation by pulsed streamer discharge in air. Appl. Phys. Res. 2009; 1, 1-10. 